\title{
The Effect of Workmanship on the Transmission of Airborne Sound through Light Framed Walls
}

\author{
J.W. Trevathan, J.R. Pearse \\ Department of Mechanical Engineering, University of Canterbury, Christchurch, New Zealand
}

\begin{abstract}
A study of the airborne sound transmission in a multi-tenanted building has shown that parts of the building which are nominally identical do not have the same acoustic performance. It was seen that some of this variation in performance could be attributed to visually-observable differences in the constructions. Some of the variation could not be explained however, and it was concluded that this variation was due to workmanship. The level of this variation was seen to be approximately $1 \mathrm{~dB}$ for a light framed construction. This variation is considerably less than that measured previously for a monolithic construction.
\end{abstract}

\section{Introduction}

Measurements are commonly made to quantify the sound insulation provided by built structures. Different results are often obtained for similar structures. These differences may be due to observable differences in the structures, the measurement procedure, or the standard of workmanship used.

Variation due to observable differences in the structures can often be identified and eliminated. Variation due to the measurement procedure can be minimised by using an identical experimental procedure and appropriate equipment for all measurements. The variation in performance of built structures due to workmanship remains a factor of considerable practical importance. 
This work used a large number of on-site measurements to assess the variation in the sound transmission loss of light framed walls due to workmanship. The sound transmission loss of the common steel framed wall between 12 pairs of rooms was measured. Repeat measurements were also undertaken on a single steel framed common wall to allow the variation due to the measurement procedure to be quantified.

\section{Experimental Procedure}

Sound transmission loss measurements were made on a number of steel framed inter-tenancy walls within a multi storied building. Each wall consisted of a $89 \mathrm{~mm}$ steel frame clad with two layers of 13 mm plasterboard on each side, with fibreglass batts installed in the wall cavity. The walls had been plastered, painted and allowed to cure for 14 days. Twelve walls were selected, separating pairs of dwellings within the multi storied building. The common wall separating the dwellings had an area of $10.95 \mathrm{~m}^{2}$. The volume of first room was $46.6 \mathrm{~m}^{3}$, and the volume of the second room was $49.8 \mathrm{~m}^{3}$. Each pair of dwellings was nominally identical, with the same common wall.

The sound transmission loss of each common wall was measured. The sound transmission loss of a designated control wall was measured 12 times, at intervals throughout the testing program. The sound transmission loss of the 11 other test walls was measured once.

The sound transmission loss of the walls was measured in accordance with the current New Zealand Building Code [1] which references ASTM E 336 [2]. The sound pressure level was measured in the source room using a third octave band real-time analyser, with a microphone placed at six different positions. A single source position was used, 1.45 metres above the floor. The sound pressure level was measured in the receiving room with a microphone placed at six different positions. The reverberation time of the receiving room was measured at three different locations, with 3 decays measured at each location. Identical microphone and source locations were used in each test for all the rooms.

From the measured data the field sound transmission loss (FSTL) of each wall was calculated for third octave bands from 50 to $10,000 \mathrm{~Hz}$ using the equation 
where

$\mathrm{L}_{\mathrm{s}}$ is the sound pressure level in the source room

$\mathrm{L}_{\mathrm{r}}$ is the sound pressure level in the receiving room

$S \quad$ is the surface area of the receiving room

$\left(\mathrm{m}^{2}\right)$

and

$$
A=0.16 V / T
$$

where

$$
\begin{aligned}
& V \quad \text { is the volume of the receiving room } \\
& T \quad \text { is the reverberation time of the receiving room }
\end{aligned}
$$$$
\left(\mathrm{m}^{3}\right)
$$

Sound intensity measurements were also made over the transmitting surfaces within the receiving room for several of the room pairs using a sound intensity probe.

\section{Results}

The 12 field sound transmission loss curves calculated from the measurements of the control wall are shown in figure 1 . The 12 sound transmission loss curves calculated from the measurements of the 11 test walls, along with the average result for the control wall, are shown in figure 2. 


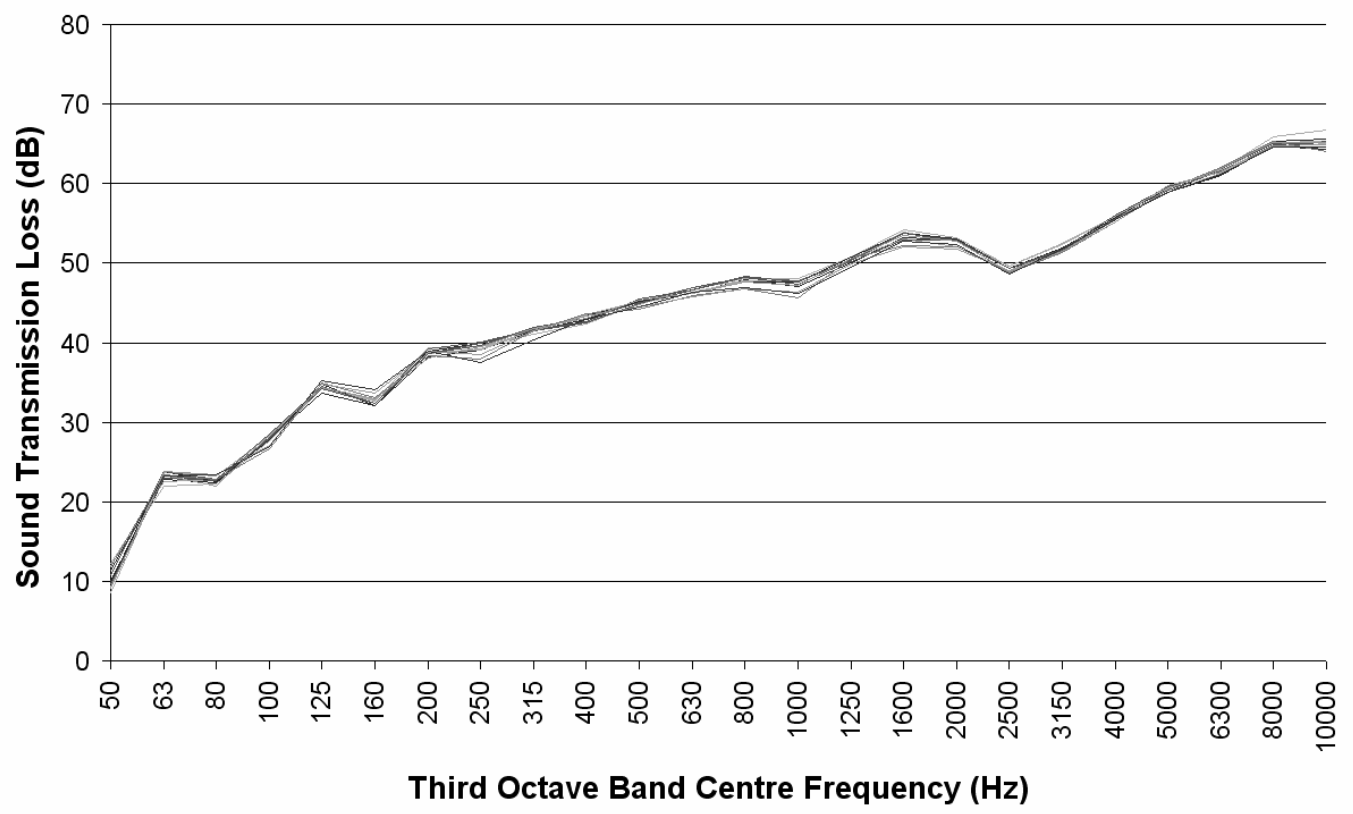

Figure 1 - The measured sound transmission loss curves for the control wall

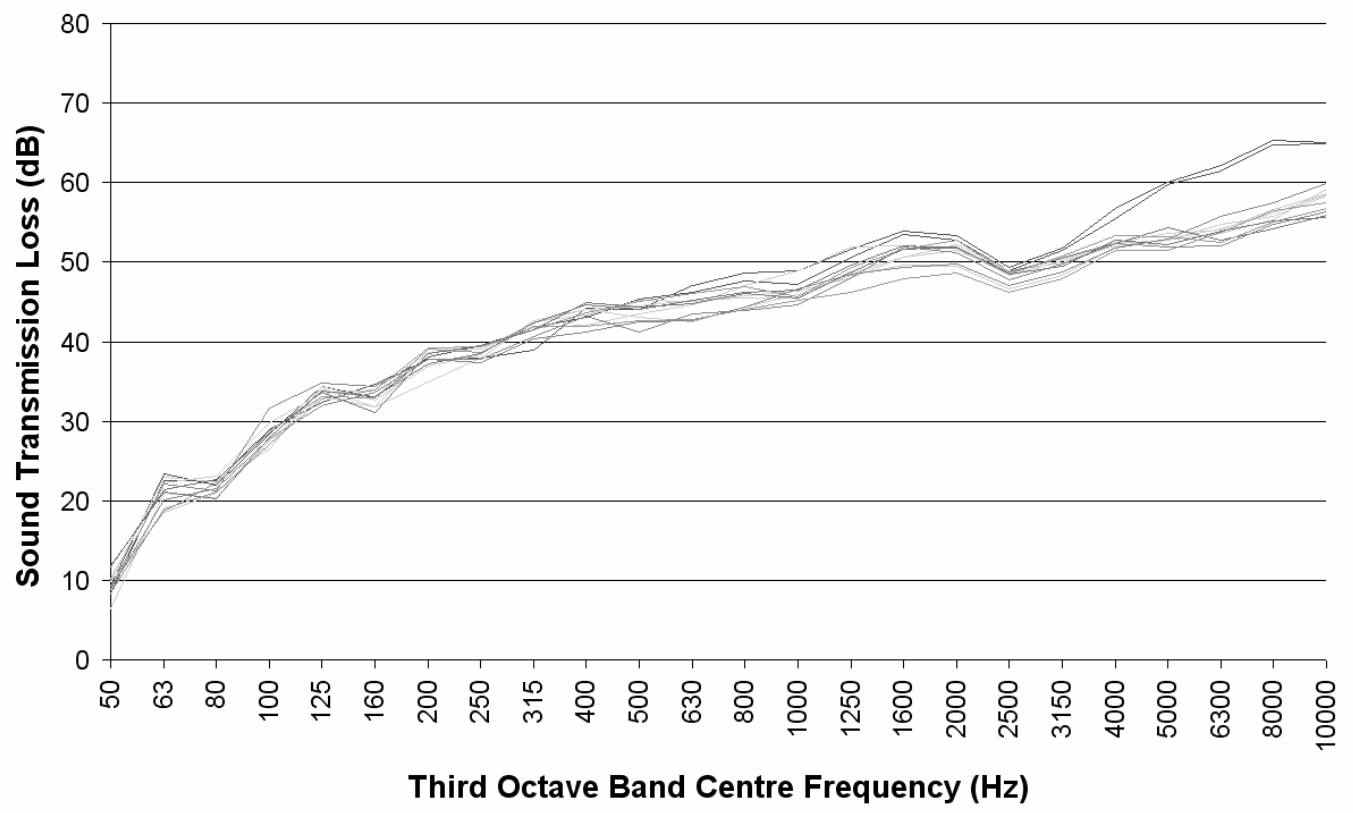

Figure 2 - The measured sound transmission loss curves for the test walls

There is clearly more variation between the results for the 12 test walls, compared to the results for the control wall. In particular, two of the 12 test walls performed significantly better than the other 10 walls 
at higher frequencies. Sound intensity measurements were made over several of the transmitting surfaces of the receiving room for both a wall which preformed well at higher frequencies, and a wall which preformed poorly at higher frequencies. These measurements showed that the sound insulation of the 10 poorly performing walls was degraded by the transmission of noise through a particular corner region, through which a drain pipe runs within the wall. This pipe is in very close proximity to the plasterboard cladding on each side of the wall.

It was concluded that for the 10 poorly performing walls the pipe was acting as a structural transmission path between the rooms, significantly degrading the acoustic isolation of the dwellings at high frequencies. It seems this problem was avoided for the two better performing walls, which were constructed first. The sound transmission loss results for the two better performing walls were excluded from the reminder of the analysis as the variation between these two results, and the results for the 10 poorly performing walls, was not judged to be generally representative of common variations due to workmanship. Rather, the variation between the results was very specific to the construction studied. Thus the study proceeded using the results for the remaining 10 test walls, and the 12 control wall results.

The standard deviation, $s$, is a measure of the variation in the results. The standard deviation of the 12 control wall results and the 10 test wall results was computed for each third octave band using the equation

$$
s=\sqrt{\frac{\sum F T L_{i}^{2}-\left(\sum F T L_{i}\right)^{2} / n}{n-1}}
$$

where $n$ is the number of walls tested.

The standard deviation of both sets of results is shown in figure 3 . 


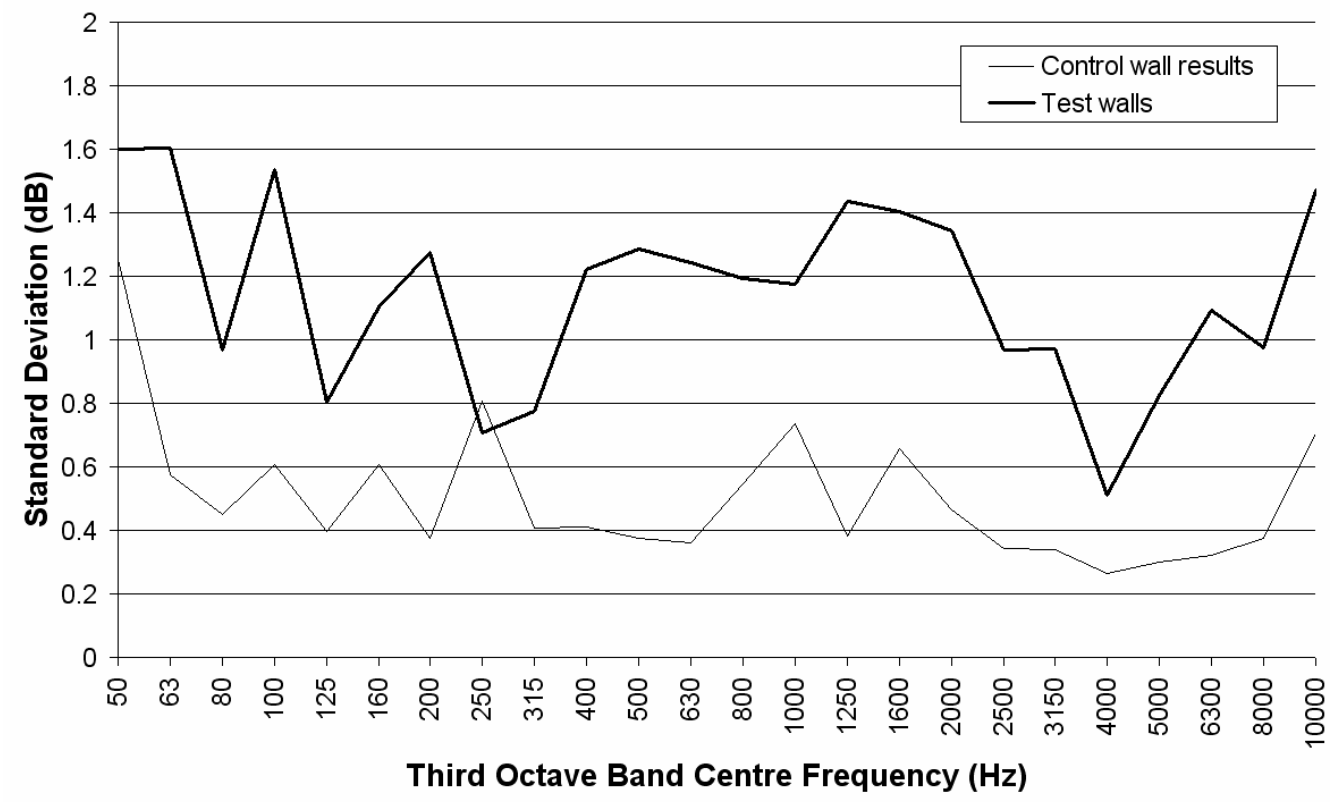

Figure 3 - Standard deviation of the test and control wall results

The standard deviation of the control wall results is a measure of the repeatability of the test procedure and is seen to remain reasonably constant over the frequency range considered. The average standard deviation for the control wall results was $0.55 \mathrm{~dB}$. This was calculated by averaging the variances for each third octave band. 


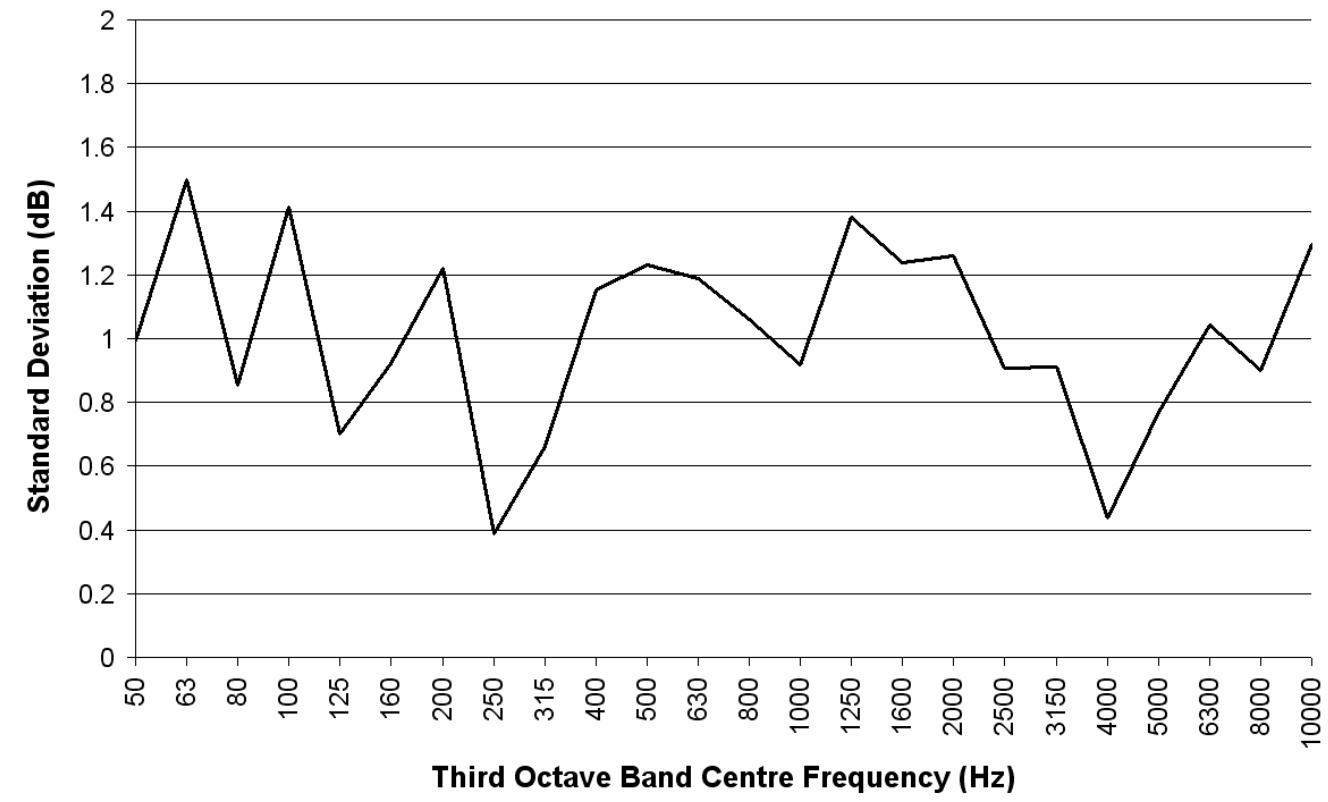

Figure 4 - The standard deviation in the sound transmission loss of steel framed walls due to workmanship

The standard deviation of $1.18 \mathrm{~dB}$ for the test walls is seen to be consistently higher than that for the control wall results. This result was expected since the test wall deviations are due to both the measurement procedure and workmanship. The control wall deviations are due solely to the measurement procedure.

By subtracting the measurement variance, the standard deviation in transmission loss due to workmanship was calculated, and is shown in figure 4. The average standard deviation of the sound transmission loss of steel framed walls due to workmanship was calculated to be $1.1 \mathrm{~dB}$. This variation, although small, is still significant.

\subsection{Comparisons with literature}

The variations due to workmanship calculated in this study for steel framed walls were compared to those calculated by Craik and Steel [3] for concrete floors. Figure 5 shows the standard deviation of the results 
obtained for the control wall in this study, along with those obtained by Craik and Steel [3] for 10 control floor measurements.

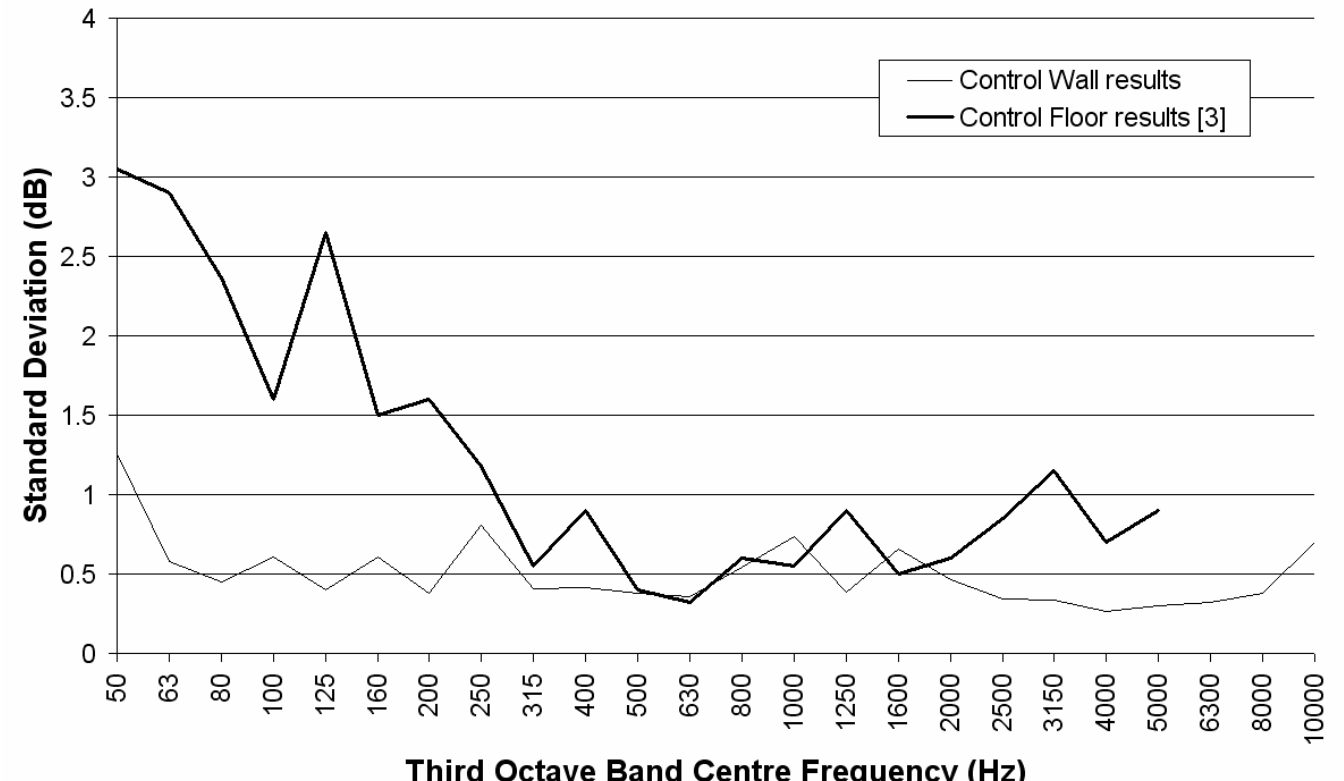

Third Octave Band Centre Frequency (Hz)

Figure 5 - Standard deviation of control wall results and control floor results from [3]

Since the standard deviation of the control wall or floor results is a measure of the repeatability of the test procedure, the figure shows that the test procedure used in this study had a repeatability which was superior to the test procedure used by Craik and Steel. This may be due to the variation in floor and room sizes used by Craik and Steel, where the sizes of the floors ranged from 6.6 to $6.8 \mathrm{~m}^{2}$, and the volumes of the corresponding rooms ranged from 20.7 to $21.5 \mathrm{~m}^{3}$. It is unclear whether Craik and Steel used identical measurement positions in each test. By limiting the frequency range to between 250 and $5000 \mathrm{~Hz}$, a standard deviation of $0.73 \mathrm{~dB}$ was calculated by Craik and Steel for the control floor measurements.

Figure 6 shows the standard deviation in the sound transmission loss of steel framed walls due to workmanship calculated in this study, along with the standard deviation in the sound transmission loss of pre-cast concrete floors due to workmanship calculated in [3]. 


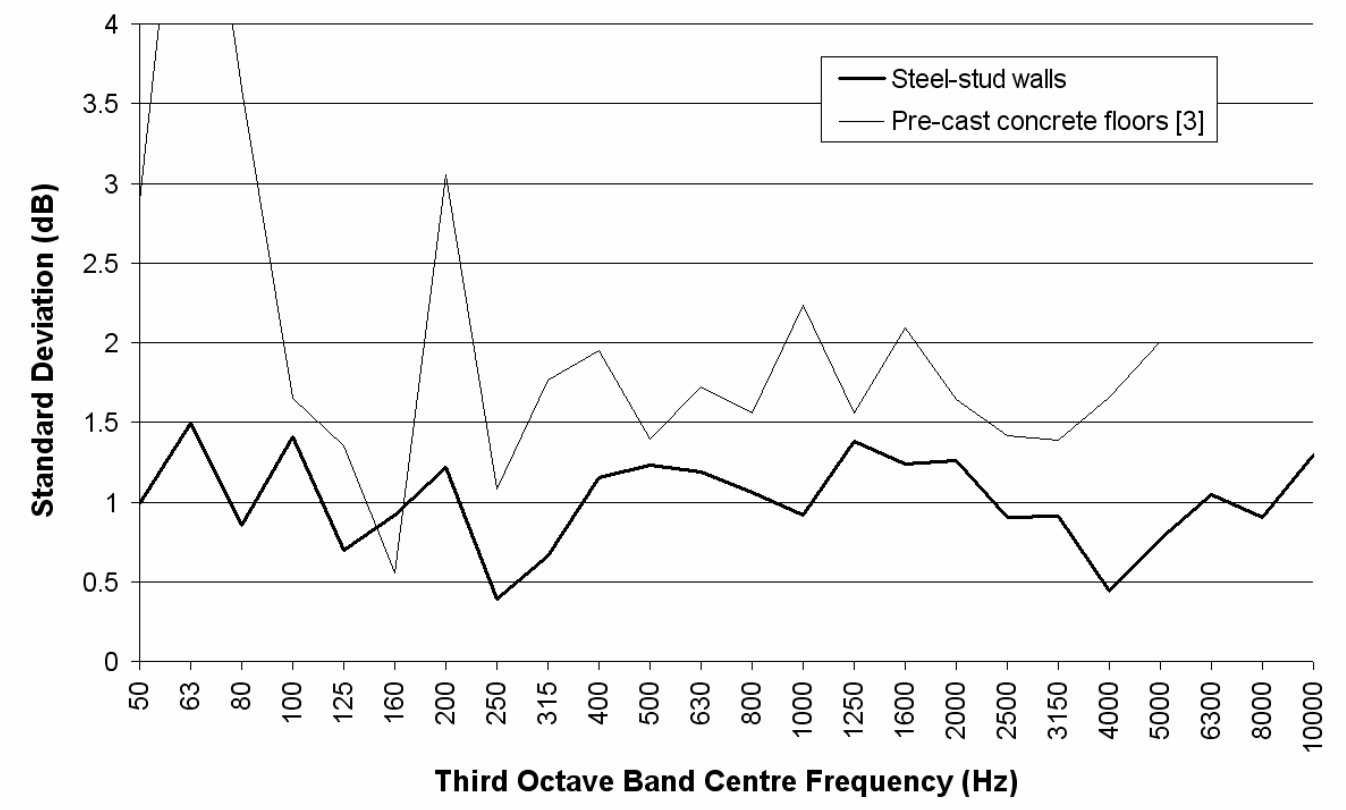

Figure 6-The standard deviation in the sound transmission loss of steel framed walls and pre-cast concrete floors due to workmanship

Craik and Steel measured an average variation in the sound transmission loss of concrete floors due to workmanship corresponding to a standard deviation of $1.7 \mathrm{~dB}$ (over a frequency range from 250 to 5000 $\mathrm{Hz}$ ). This standard deviation is significantly higher than that measured in this study for steel framed walls $(1.1 \mathrm{~dB})$.

\subsection{Conclusions}

Workmanship caused a variation in sound transmission loss for the steel framed walls in the building tested corresponding to a standard deviation of $1.1 \mathrm{~dB}$ on average, for a given third octave band. This variation is less significant than that reported in the literature for pre-cast concrete floors $(1.7 \mathrm{~dB})$.

\subsection{References}


[1] New Zealand Building Code, Airborne and Impact Sound - Clause G6, Building Industry Authority, 2001.

[2] ASTM E 336 - 90, Standard Test Method for Measurement of Airborne Sound Insulation in Buildings, American Society for Testing and Materials, 1990.

[3] Craik R.J.M. and Steel J.A., The Effect of Workmanship on Sound Transmission through Buildings: Part 1 - Airborne Sound, Applied Acoustics, Volume 27, pp 57 - 63, 1989. 